\title{
Avaliação de diferentes vias vacinais para vacinação contra o vírus da doença de Newcastle em aves de fundo de quintal
}

[Assessment of different vaccination approaches against Newcastle disease virus in domestic backyard poultry]

\author{
S.R. Câmara ${ }^{1}$, W.M. Cardoso ${ }^{2 *}$, R.S.C. Teixeira ${ }^{3}$, J.M. Romão ${ }^{4}$, A.A. Siqueira ${ }^{4}$, R.P.R. Salles ${ }^{3}$, E.E. Silva ${ }^{4}$, \\ G.C. Nogueira ${ }^{4}$, C.C. Campello ${ }^{2}$, F.M. Sousa ${ }^{2}$, T.G.V. Moraes ${ }^{4}$ \\ ${ }^{1}$ Aluna de pós-graduação - RENORBIO - Fortaleza, CE \\ ${ }^{2}$ Faculdade de Veterinária - FV-UECE - Fortaleza, CE \\ ${ }^{3}$ Aluno de pós-graduação - FV-UECE - Fortaleza, CE \\ ${ }^{4}$ Aluno de graduação - FV-UECE - Fortaleza, CE
}

\begin{abstract}
RESUMO
Foram avaliadas três vias de aplicação vacinal contra o vírus da doença de Newcastle em aves de criatório de fundo de quintal (AFQ) jovens e adultas. Um total de $135 \mathrm{AFQ}$ foram distribuídas em tratamentos distintos de acordo com a via vacinal: via ocular (VO), água de bebida (VAB) e alimentar (VA). Cada tratamento foi representado por 40 aves ( 20 jovens e 20 adultas) e utilizou-se um grupo-controle de 15 aves não vacinadas. $\mathrm{O}$ programa de vacinação estabelecido constou de uma primovacinação $\mathrm{e}$ dois reforços vacinais, utilizando-se a cepa La Sota. Para aves jovens, os títulos obtidos pelas VO e VAB não diferiram aos 15, 45 e 140 dias, mas houve diferenças nos títulos das aves vacinadas pela VA. Nas aves adultas, a vacinação pela $\mathrm{VO}$ apresentou resultados mais elevados que as vacinações pelas VAB e VA na primeira resposta, aos 15 dias. Aos 45 dias, os títulos obtidos pela VAB foram mais baixos que os obtidos pela VO, e, aos 140 dias, não houve diferença entre as três vias avaliadas. Concluiu-se que as vacinações pelas $\mathrm{VO}$ e VAB constituem alternativas eficazes para vacinação de AFQ jovens e adultas.
\end{abstract}

Palavras-chave: aves de fundo de quintal, Newcastle, resposta imuno-humoral

\begin{abstract}
Three ways of vaccination against Newcastle Disease Virus (NDV) were evaluated in young and adults domestic backyard poultry (DBP). A total of 135 DBP was submitted to three different administration routes of ND vaccine: eye-drop, drinking water, and feed. Each treatment consisted of 40 birds (20 young and 20 adult) and a control group of 15 unvaccinated birds. The treatment consisted of a first vaccination and two boosters, using La Sota strain. For young birds, the eye-drop and drinking water vaccinations presented no differences at 15, 45, and 140 days, differing from the titers obtained by birds treated by feed vaccination method. In the adult birds, the eye-drop administration presented higher titers than by drinking water and feed approaches in the first response to the vaccination at 15 days. At 45 days, the results obtained by the drinking water had lower titers than those from the eye-drop. The three vaccination methods presented no difference at 140 days. In conclusion, the vaccination by eye-drop and drinking water methods constituted an efficient alternative of vaccination for adult and young DBP against Newcastle virus.
\end{abstract}

Keywords: domestic backyard poultry, Newcastle, humoral immune response

Recebido em 6 de novembro de 2008

Aceito em 30 de setembro de 2009

Autor para correspondência (corresponding author)

E-mail: william.maciel@uol.com.br 


\section{INTRODUÇÃO}

Vários autores afirmam que a doença de Newcastle (DN) é um dos principais problemas sanitários que afetam a indústria avícola mundial em virtude das grandes perdas econômicas que ocasionam (Paulillo e Doretto Jr., 2002; Biswas et al., 2005; Kapezynsky e King, 2005). Pesquisas realizadas em países da África e Ásia e na Austrália citam a DN como a maior causa de mortalidade em aves de criatórios de fundo de quintal (AFQ). Segundo Spradbrow (1994), em países africanos, surtos anuais da DN são responsáveis pela mortalidade de $70-80 \%$ de aves não vacinadas. Facon et al. (2005) afirmam que o vírus da doença de Newcastle (VDN) acarreta danos à produção de AFQ e constitui uma limitação para a manutenção desses sistemas de produção.

$\mathrm{Na}$ avicultura industrial, a DN é controlada pelas vacinações contra o VDN, entretanto o segmento avícola brasileiro representado pelos criadores de AFQ não dispõe de metodologia de prevenção da doença que considere os hábitos culturais do criador, as características dos sistemas de criação, a usual incorporação ao plantel de aves com condição sanitária não conhecida e o arraçoamento (Jorge et al., 1998).

Diversas pesquisas realizadas em países africanos e na Austrália avaliaram a eficácia de vacinação contra a $\mathrm{DN}$ em $\mathrm{AFQ}$ por meio das amostras V4 e I2 usando vias vacinais alternativas, mediante uma grande variedade de alimentos e vias convencionais. Porém, essas amostras não estão disponíveis no mercado brasileiro (Alexander et al., 2004).

Desse modo, este trabalho teve por objetivo comparar a soroconversão de AFQ jovens e adultas por meio de três vias de administração de vacinas mediante a estirpe La Sota e estimar os intervalos de revacinações contra a DN.

\section{MATERIAL E MÉTODOS}

Foram utilizadas 150 AFQ, de origem genética desconhecida e idades iniciais de cerca de três e seis meses para aves jovens e adultas, respectivamente, provenientes de criatórios particulares e de feiras livres do município de Cascavel, situado a $52 \mathrm{~km}$ de Fortaleza, Ceará. Estas aves foram criadas em regime semi- intensivo de criação com densidade menor que uma ave por $\mathrm{m}^{2}$ e foram alojadas em galpões experimentais em uma propriedade localizada no município de Pindoretama, situado a $45 \mathrm{~km}$ de Fortaleza. Durante todo o período experimental, as aves foram alimentadas com ração comercial, frutas, hortaliças, gramíneas e água ad libitum.

Um total de 135 AFQ foram submetidas a três tratamentos, os quais diferiram em relação à via de administração utilizada: via ocular (VO), água de bebida (VAB) e alimentar (VA). As vias de administração (tratamentos) foram representadas por 40 aves, 20 jovens (até três meses de idade) e 20 adultas (até seis meses de idade), identificadas individualmente com anilhas numeradas. Houve também um grupo-controle (GC) de aves não vacinadas representado por 15 animais.

Para vacinar pela VAB, foi adotado o protocolo proposto por Thekisoe et al. (2004), mediante o qual as aves foram submetidas a um jejum hídrico de 14 horas antes da administração da vacina. Para o preparo da vacina, 1000 doses da vacina liofilizada foram diluídas em $1000 \mathrm{~mL}$ de água destilada. Após a dissolução, uma alíquota de $80 \mathrm{~mL}$ de solução vacinal foi rediluída em $240 \mathrm{~mL}$ de água destilada, adicionado leite em pó desnatado na proporção de $2 \mathrm{~g} / \mathrm{mL}$ de solução, seguindo de imediata distribuição em bebedouros. Cada ave recebeu aproximadamente $8 \mathrm{~mL}$ de solução vacinal, conforme Alexander et al. (2004), resultando na administração média de duas doses por ave.

A VO foi preparada no momento da vacinação em que 1000 doses da vacina liofilizada foram diluídas em $30 \mathrm{~mL}$ de diluente industrial. Cada ave recebeu duas gotas oculares correspondendo a $0,06 \mathrm{~mL}$ sendo em média duas doses por ave.

O protocolo utilizado pela via alimentar consistiu na utilização de $2 \mathrm{~kg}$ de milho triturados (fubá grosso), de boa qualidade e livres de impurezas. Estes passaram por uma fervura rápida, $15 \mathrm{~min}$ em $2 \mathrm{~L}$ de água, e permaneceram over night até o momento da vacinação (Thekisoe et al., 2004). Nos dias destinados às vacinações, os animais não foram alimentados pela manhã, com o intuito de provocar um jejum alimentar de 16 horas (Jorge et al., 1998). Para o preparo da vacina, 1000 doses foram diluídas em $1000 \mathrm{~mL}$ de água destilada. Uma alíquota de $80 \mathrm{~mL}$ da suspensão vacinal foi homogenizada com uma colher de 
plástico grande e adicionada ao milho fervido e resfriado over night. Em seguida, o preparo foi distribuído em comedouros, resultando na administração em média de duas doses por ave (Thekisoe et al., 2004).

Dez frascos de vacinas contra o VDN de 1000 doses cada, liofilizado ${ }^{1}$, e dentro do prazo de validade, foram adquiridos no comércio especializado local. A partir de um mesmo frasco das dez vacinas adquiridas contendo a estirpe La Sota (título $\geq 10^{6,5}$ DIE50), foi realizada a titulação em ovos embrionados de galinhas specific pathogen free (SPF) conforme metodologia descrita por Hitchner et al. (1975). O programa de vacinação contra a DNC constou de uma primeira vacinação e dois reforços efetuados com 15 e outro com 90 dias, utilizando-se as vias de administração VO, VAB e VA. As coletas de sangue foram realizadas com 1 , $15,45,105$ e 140 dias.

A sorologia pareada procedeu de aves do mesmo grupo nas cinco coletas de sangue realizadas, resultando em 10 aves jovens e 10 adultas de cada via de administração (tratamento) e 10 aves do grupo-controle.

O sangue foi obtido por venopunção aspirativa, retirando-se $3,0 \mathrm{~mL} /$ ave da veia braquial. Três horas após a retração do coágulo, os soros foram separados, identificados, acondicionados em isopor com gelo biológico e remetidos ao laboratório para realização da prova sorológica.
Foi utilizado o teste de inibição da hemaglutinação (IH) para detecção de anticorpos séricos contra o VDN, proposto por Beard e Hanson (1984), no qual a quantidade de vírus é mantida constante, enquanto o soro inativado $\left(56^{\circ} \mathrm{C} / 30 \mathrm{~min}\right)$ é diluído em série. $\mathrm{O}$ teste IH/VDN foi realizado em microplacas fundo em ' $\mathrm{v}$ ' de 96 orifícios, com diluição inicial de 1:2. $\mathrm{O}$ antígeno foi diluído em quatro unidades hemaglutinantes (UHA), e os títulos expressos em $\log _{2}$.

Os títulos de IH/VDN obtidos das amostras de soro das aves foram transformados em títulos médios geométricos (GMT) em $\log _{2}$, e as médias foram calculadas por tratamento e via de administração utilizada. Realizaram-se as análises de variâncias por meio do procedimento GLM do SAS/1999, e as médias das variáveis respostas para cada tratamento experimental foram comparadas por meio do teste Duncan, de acordo com os critérios estabelecidos por Sampaio (2002). As médias foram consideradas significativamente diferentes quando $\mathrm{P}<0,05$, e os resultados foram apresentados como média \pm desviopadrão.

\section{RESULTADOS E DISCUSSÃO}

Não foram detectados anticorpos IH/VDN nas aves jovens antes da primovacinação para as três vias avaliadas, e as aves pertencentes ao grupo-controle apresentaram títulos negativos durante todos os meses avaliados (Fig. 1). Desse modo, a detecção de anticorpos IH/VDN nas aves relacionou-se diretamente com a vacinação segundo Jorge et al. (1998).

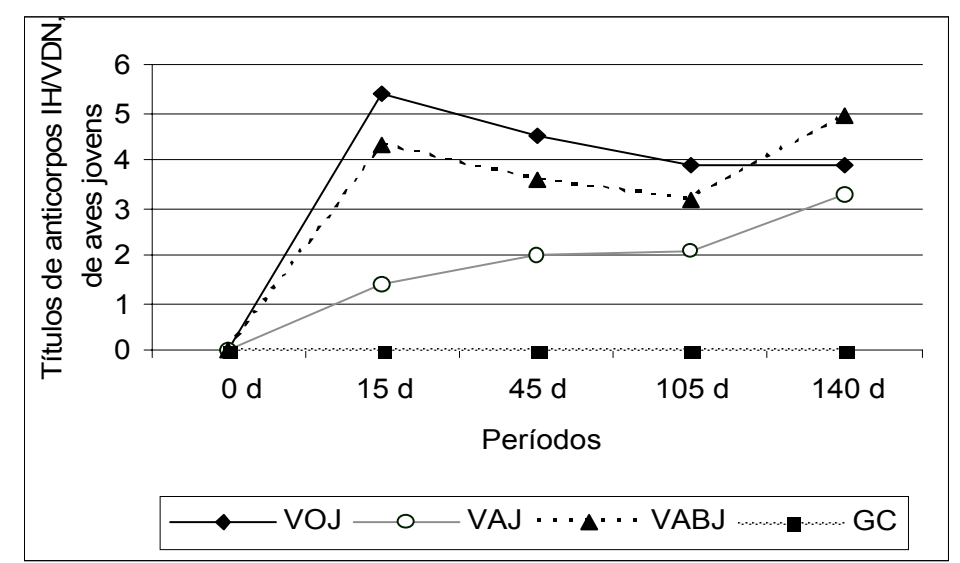

VOJ: via ocular; VAJ: via alimentar; VABJ: via água de bebida; GC: grupo-controle.

Figura 1. Títulos de anticorpos contra o vírus da doença de Newcastle em aves jovens vacinadas pelas vias ocular, alimentar e água de bebida.

${ }^{1}$ Merial - Campinas, Brasil. (partida/lote 002/05). 
A estirpe lentogênica La Sota é usada em diversos países do mundo, e a extensa literatura envolvendo essa cepa reporta que ela é bemsucedida pelas vias ocular e água de bebida (Bacallao et al., 1998). Os resultados obtidos confirmam os já encontrados por esses autores, isto é, aves jovens vacinadas pelas vias ocular e água de bebida não apresentaram diferenças significativas durante todos os períodos avaliados, quanto ao título.

Nas respostas às vacinações avaliadas aos 15, 45 e 140 dias, não houve diferenças $(\mathrm{P}>0,05)$ nos títulos das aves jovens entre as $\mathrm{VO}$ e VAB, diferindo, entretanto, dos títulos obtidos nas aves vacinadas pela via alimentar. Segundo AmakyeAnim et al. (1998), o processo de imunização, com vacinas preparadas com as cepas V4 e/ou I1 (Wilcox, 1999), pelas vias ocular e água de bebida tem resultado em títulos mais altos de anticorpos que a vacinação pela via alimentar, alcançando proteção satisfatória com uma dose. Thekisoe et al. (2004), ao avaliarem diferentes vias de administração de vacinas, concluíram que os títulos médios de anticorpos IH/VDN das aves vacinadas pela VA foram significativamente mais baixos quando comparados por outras vias.
Segundo o autor, é possível que a vacina não se dissolva bem quando misturada aos grãos, pois a via alimentar não faz parte das vias recomendadas pelos fabricantes da vacina e, ainda, as aves não ingerem doses exatas quando esta é fornecida. Assim, aves adultas costumam ingerir maior quantidade como sinal de dominância, intimidando as aves jovens. Entretanto, por se tratar de vacina contendo vírus vivo naturalmente apatogênico (estirpe La Sota) e, apesar dessa condição, infecto-contagioso, a circulação desse vírus no lote vacinado certamente ocorreu, e os objetivos de sua utilização foram atingidos.

A exemplo do que ocorreu nas aves jovens, anticorpos IH/VDN não foram detectados nas aves adultas antes da primovacinação para as três vias avaliadas. As três vias vacinais (VO, VAB e VAL) apresentaram diferenças $(\mathrm{P}<0,05)$ na resposta dos títulos de anticorpos IH/VDN quando comparadas com o título do grupocontrole (Fig. 2). Desse modo, as aves adultas vacinadas, por estarem desprovidas de sólida imunidade, teriam sofrido a infecção vacinal, resultando em ativa resposta sorológica (Jorge et al., 1998).

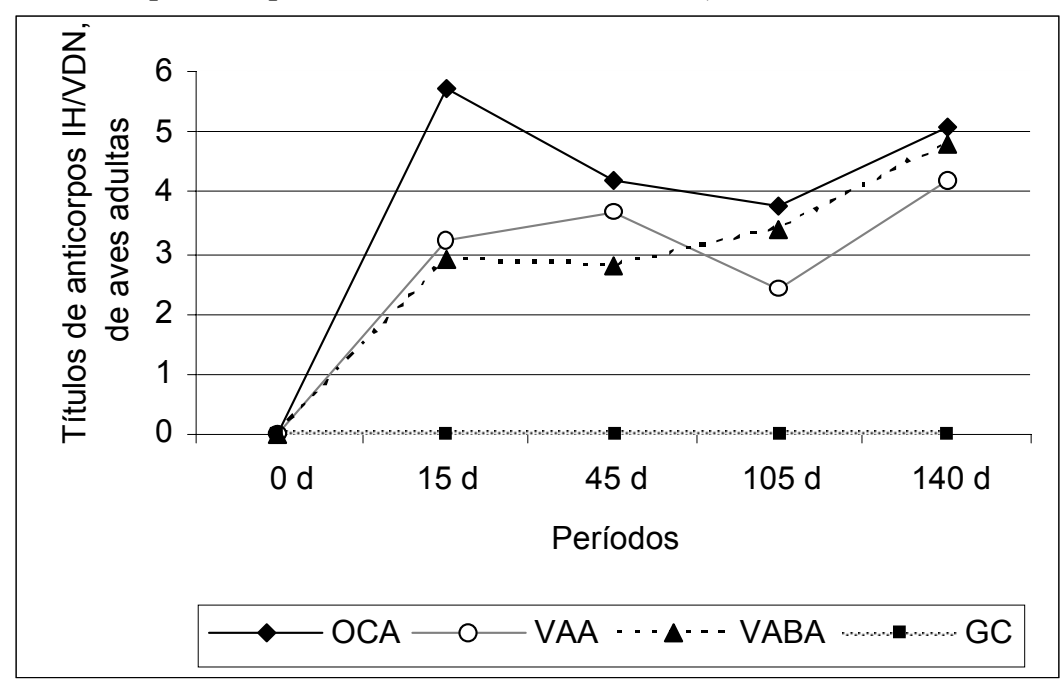

OCA: via ocular; VAA: via alimentar; VABA: via água de bebida; GC: grupo-controle.

Figura 2. Títulos de anticorpos contra o vírus da doença de Newcastle $\left(\log _{2}\right)$ em aves adultas vacinadas pelas vias ocular, alimentar e água de bebida.

As três vias de administração de vacinas elevaram os títulos de anticorpos IH/VDN nas aves adultas após estímulo vacinal. Estes resultados diferem dos obtidos por Paulillo et al.
(1987), que afirmam que a resposta imune é improvável em aves velhas com níveis de anticorpos em queda e sistema imune maduro, e, ainda, dos obtidos por Jorge et al. (1998), os 
quais afirmam que a imunidade em aves velhas, com mais de um ano de idade, seria contida pela imunidade preexistente, sem provocar reforço imunológico perceptível pelo teste de IH.

A vacinação pela VO nas aves adultas apresentou resultados mais altos que pelas VAB e VA na primeira resposta à vacinação aos 15 dias. Aos 45 dias, os resultados obtidos pela $\mathrm{VAB}$ foram mais baixos que os obtidos pela $\mathrm{VO}$, $\mathrm{e}$, aos 140 dias, não houve diferença significativa entre as três vias avaliadas $(\mathrm{P}<0,05)$. Resultados semelhantes tinham sido obtidos por Rehmani (1996) que ao avaliar, por sete semanas, a eficácia da estirpe La Sota pelas VO e VAB, verificou que a vacinação pela $\mathrm{VO}$ apresentou melhores resultados na terceira, na quarta e na quinta semanas, com significativo decréscimo $(\mathrm{P}<0,05)$ dos títulos médios de anticorpos na sexta semanas e sétima semanas para as duas vias avaliadas.

Decorridos três meses após o segundo estímulo vacinal, os títulos de anticorpos IH/VDN das aves que foram imunizadas pelas $\mathrm{VO}$ e VAB não diferiram entre si, sendo diferentes, entretanto, dos títulos oriundos de aves vacinadas pela VA $(\mathrm{P}<0,05)$. Assim como ocorrido nas aves jovens, a vacinação pela VA provocou elevação tardia nos títulos de anticorpos IH/VDN. De acordo com Oakaley (2000), a eficácia de grãos na administração de vacinas é altamente variável. Resultados obtidos com os mesmos grãos, nas condições sugeridas, apresentaram resultados divergentes (Rushton, 1995). Convém ressaltar ainda que os números de aplicações de vacinas requeridas para alcançar bons níveis de proteção também têm sido variáveis (Samuel et al., 1993).

Os títulos de anticorpos IH/VDN das aves jovens e adultas vacinadas pelas três vias de administração demonstraram decréscimo na terceira e quarta coletas. As aves foram revacinadas após a quarta coleta, em fevereiro, e houve aumento na resposta dos títulos de anticorpos IH/VDN nas três vias de administração. Segundo Palya (1998), o intervalo de revacinações para atingir um nível de proteção satisfatório em aves vacinadas pela VA é variável, sendo necessárias de seis a oito vacinações anuais. Entretanto, os resultados obtidos neste trabalho podem sugerir a necessidade de revacinações decorridos três a quatro meses após a primeira revacinação.
Resultados semelhantes foram encontrados por Thekisoe et al. (2004), que avaliaram a eficácia da vacina nobilis Inkuku ${ }^{\circledR}$ em AFQ nas três vias de administração utilizadas neste trabalho, e por Biswas et al. (2005), que estudaram a eficácia de estirpes lentogênicas pelas VO e VAB em vacinação de AFQ. Diante dos resultados apresentados, pode-se concluir que a vacinação pelas vias ocular e água de bebida constituem alternativas eficazes para vacinação de AFQ jovens e adultas, com intervalos de revacinações estimados de três meses.

\section{AGRADECIMENTOS}

A primeira autora agradece à Fundação Cearense de Apoio ao Desenvolvimento Científico e Tecnológico - Funcap -, pelo apoio financeiro (Bolsa) durante a realização do mestrado. Ao Laboratório Biolab S/C Ltda. e à Dra. Rosa Patrícia Ramos Salles, pelo auxílio nas provas sorológicas, e ao Laboratório de Estudos Ornitológicos da Faculdade de Veterinária da UECE. Ao Sr. João Bosco da Câmara e esposa, pela concessão da propriedade, aquisição dos animais e financiamento da ração durante todo o período experimental.

\section{REFERÊNCIAS BIBLIOGRÁFICAS}

ALEXANDER, D.J.; BELL, J.G.; ALDERS, R.G. (Eds.). Technology review: Newcastle disease. Roma: FAO, 2004. (FAO Animal Production and Health. Paper, 161).

AMAKYE-ANIM, J.; ALDERS, R.G.; SPRADBROW, P.B. (Eds.). Trials with V4 Newcastle disease vaccine in Ghana. In: ASIA PACIFIC POULTRY CONFERENCE, 4., 1998, Melbourne. Scientific proceedings... Melbourne: Australian Veterinary Poultry Association, 1998. $43 \mathrm{p}$.

BACALLAO, A.; PILAR, H.; VIAMONTES, O. Statistical evaluation of the results of IH test in broilers vaccinated against ND by aerosol or through drinking water. Rev. Cubana Cienc. Avic., v.15, p.59-65, 1998.

BEARD, C.W.; HANSON, R.P. Newcastle disease. In: HOFSTAD, H.J.; BARNES, B.W.; CALNEK, W.M. et al. (Eds.). Diseases of poultry. Ames: Iowa State University, 1984. p.452-470. 
BISWAS, P.K.; BISWAS, D.; AHMED, S. et al. A longitudinal study of the incidence of major endemic and epidemic diseases affecting semiscavenging chickens reared under the Participatory Livestock Development Project areas in Bangandesh. Avian Pathol., v.34, p.303$312,2005$.

FACON, C.; GUERIN, J.L.; LACROIX, F. Assessment of Newcastle disease vaccination of houbara bustard breeders (Chlamydotis undulate undulate). J. Wildl. Dis., v.41, p.768-774, 2005.

HITCHNER, S.B.; DOMERMUTH, C.H.; PURCHASE, H.G. Isolation and Identification of avian patrhogens. Ithaca: The American Association of avian Pathologists, 1975. p.337345.

JORGE, M.A.; MARTINS, N.R.S.; RESENDE, J.S. Vacinação de galinhas fundo de quintal contra a doença de Newcastle com vacina veiculada por milho. Arq. Bras. Med. Vet. Zootec., v.50, p.123-126, 1998.

KAPEZYNSKY, A.R.; KING D.J. Protection of chickens against overt clinical disease and determination of viral shedding following vaccination with commercially available Newcastle disease virus vaccines upon challenge with highly virulent virus from the California 2002 exotic Newcastle disease outbreak. Vaccine, v.23, p.3424-3433, 2005.

OAKALEY, R.D. The limitations of a feed: water based heat-stable vaccine delivery system for Newcastle disease-control strategies for backyard poultry flocks in sub-Saharan Africa. Prev. Vet. Med., v.47, p.271-279, 2000.

PALYA, V.J. (Ed.). Assistance for the control of Newcastle disease plane II: Consultance report on feed-besed Newcastle disease vaccine. Rome: FAO, 1998. 22p.

PAULILLO, A.C.; DORETTO Jr., L. Doença de Newcastle. In: BERCHIERI Jr., A.; MACARI, M. Doenças das aves. 2.ed. Campinas: FACTA, 2002. p.267-282.
PAUlillO, A.C.; PINTO, A.A., BERCHIERI Jr., A. et al. Newcastle disease: immune response to live vaccine (La Sota strain) and inactivated vaccine (oil-based) in broiler chicks carrying maternal antibodies. Ars Vet., v.3, p.235-242, 1987.

REHMANI, S.F. Newcastle disease vaccination: A comparison of vaccines and routes of administration in Pakistan. Prev. Vet. Med., v.25, p.241-248, 1996.

RUSHTON, J. (Ed.). Assistance to rural women in protecting their chicken flocks against Newcastle disease: Consultancy report on rural poultry production-social-economic. Rome: FAO, 1995. 71p.

SAMPAIO, I.B.M. Estatística aplicada à experimentação animal. 2.ed. Belo Horizonte: FEPMVZ, 2002. 265p

SAMUEL, J.L.; BENSINK, Z.; SPRADBROW, P.B. Oral vaccination of chickens with the V4 strain of Newcastle disease virus - cooked and raw white rice as a vehicle. Trop. Anim. Health Prod., v.25, p.2-10, 1993.

SPRADBROW, P.B. Newcastle disease in village chickens. Poult. Sci. Rev., v.5, p.57-96, 1994.

THEKISOE, M.M.O; MBATI, P.A.; BISSCHOP, S.P.R. Different approaches to the vaccination of free ranging village chickens against Newcastle disease in Qwa-Qwa. S. Afr. Vet. Microbiol., v.10, p.23-30, 2004.

WILCOX, G.E. Termostable Newcastle disease vaccines in Tanzânia. Vet. Microbiol., v.68, p.127-130, 1999. 